\title{
A Comparison of Three Pain Assessment Scales in the Assessment of Pain Among Dental Patients in Port Harcourt
}

\author{
U. Otakhoigbogie, B.B. Osagbemiro, and I. C. Egwim
}

\begin{abstract}
Proper assessment of pain is essential in evaluating the appropriate treatment need of patients presenting with dental conditions. This study aimed to determine the correlation between Short Form McGill pain questionnaire 2 (SF-MPQ-2), Visual analogue Scale (VAS) and Numerical Rating Scale (NRS) for pain assessment among dental patients.

A total of 83 patients that presented at the Oral Diagnosis clinic of the University of Port Harcourt Teaching Hospital with various dental conditions over 2 months were recruited for the study. The severity of the different presenting conditions was determined using SF-MPQ-2, VAS and NRS. The mean pain assessment scores for the different dental conditions was compared and Pearson correlation coefficient was evaluated for the three pain assessment scales. $P<0.05$ was considered statistically significant.

The mean age of the study participants was $38.2 \pm 14.0$ years with age range of 16 to 83 years. The mean VAS and NRS scores were significantly higher in those diagnosed with acute apical periodontitis with mean scores of $6.68 \pm 2.36$ and $6.61 \pm 2.06$ respectively. The participants with cancer had the lowest SFMPQ-2 mean scores while those with chronic periodontitis have the lowest score using VAS and NRS. There was a significant strong, positive correlation between VAS and NRS pain assessment tools. The correlation between SF-MPQ-2 and either VAS/NRS was however, weak but positive and statistically significant.

Severity of pain was highest among those with acute apical periodontitis using the three pain assessment tools. There was a significant positive correlation between SF-MPQ-2, VAS and NRS for dental pain assessment.
\end{abstract}

Index Terms - Dental pain, NRS, pain assessment, SF-MPQ2, VAS.

\section{INTRODUCTION}

Pain, though an unpleasant experience, could be of physiological or pathological origin [1]. Orofacial pain accounts for 20-58.8\% [1], [2] of the reasons for dental clinic visit, thus proper assessment of pain is essential in evaluating the appropriate treatment need of patients presenting with dental conditions. The ability of patients to express their pain sensation is often affected by psychologic, physiologic, developmental and behavioural factors [3]. Due to the difficulty in ascertaining the character and intensity of pain among patients, different pain assessment scales have been

Published on August 29, 2020.

U. Otakhoigbogie, Department of Oral Pathology and Oral Medicine, University of Nigeria, Enugu Campus, Enugu, Nigeria.

(e-mail: Otakhoigbogie37@gmail.com)

B. B. Osagbemiro, Department of Preventive Dentistry, University of Port Harcourt Teaching Hospital, Port Harcourt, Nigeria.

(corresponding e-mail: topegraphics03@yahoo.co.uk) developed such as Numerical Rating Scale (NRS), Visual analogue Scale (VAS), PAINAD, BPS, Short Form McGill pain questionnaire 2(SF-MPQ-2) [4]. While SF-MPQ-2 is used to measure the quality as well as the intensity of pain; VAS and NRS measure intensity of pain [5].

The SF-MPQ-2 is a revised version of SF-MPQ with 22 items in addition to a $0-10$ numerical rating scale (NRS) to provide increased responsiveness. It comprises of four subscales; affective subscale and three sensory subscales measuring continuous, intermittent and neuropathic pain qualities [6]. It is a reliable and valid tool for the assessment of the multidimensional qualities of pain in people with neuropathic and non-neuropathic pain conditions [6], [7]. A study by Gauthier et al. [8] demonstrated that the Short-Form McGill Pain Questionnaire-2 is valid for use in older and younger people with advanced cancer and pain. The advantage of SF-MPQ-2 lies in its ability to measure the intensity, nature and impact on activity and mood of the individual. However, some individuals still find its use to be overwhelming and complex [9], [10].

The single dimensional scales such as VRS, NRS, VAS and Wong-Baker Faces Pain Rating Scale are a simple way for patients to rate the intensity of their pain [9]. These scales are useful in assessing acute pain such as trauma, pancreatitis, acute apical periodontitis and irreversible pulpitis [10]. They have been used widely in clinical and research settings that require a quick index of pain intensity to which a numerical value can be assigned [10], [11]. However, they can oversimplify the pain experience and are often unreliable in monitoring the effect of treatment [11], [12]. Also, there are variations across different ethnicity and diagnoses [12]. The Numerical rating scale (NRS) is common and simple to use. The patient is given a range of number and asked to choose a number in relation to the pain's intensity. The advantage of NRS lies in its simplicity, reproducibility and sensitivity to small changes [12]. Visual Analogue Scale (VAS) is like NRS, except that the patient marks on a measured line in which one end represents no pain and the other end the worst imaginable pain.

Previous Nigerian studies have determined the correlation between VAS and the Full Cup Test (FCT) [2], [6]. There is paucity of literature on the use of SF-MPQ-2 in our environment. The objective of this study was to determine the

I. C. Egwim, Department of Oral pathology and Oral Diagnosis, University of Port Harcourt Teaching Hospital, Port Harcourt, Nigeria.

(e-mail: egwimic@gmail.com) 
correlation between SF-MPQ-2, VAS and NRS for pain assessment among dental patients presenting with various forms of dental pain. Also, to determine the relationship between the severity of pain at presentation by dental patients and the clinical diagnosis of their dental condition.

\section{Methodology}

This cross-sectional, descriptive study was done among patients that presented at the Oral Diagnosis clinic of the University of Port Harcourt Teaching Hospital (UPTH) with various dental conditions. Ethical approval was obtained from the Research Ethics Committee UPTH (protocol no. UPTH/ADM/90/S.II/VOL.XI/353). All the patients that presented over 2 months (November and December 2019) were recruited for the study. All participants provided informed consent prior to participation in the study. Data collection was done with the aid of structured, selfadministered questionnaires. Information was obtained on respondents' socio-demographic details and the severity of the different presenting dental conditions was assessed using SF-MPQ-2, VAS and NRS.

SF-MPQ-2 is a 22-item survey with $0-10$ NRS ( $0=$ none; 10 = worst possible). it consist of four subscales as follows: (a) continuous pain descriptors (6 items): "throbbing pain", “cramping pain", “gnawing pain”, “aching pain", "heavy pain", and "tender"; (b) intermittent pain descriptors (6 items): "shooting pain", "stabbing pain", "sharp pain", "splitting pain," "electric-shock pain", and "piercing"; (c) predominantly neuropathic pain descriptors (6 items): "hotburning pain", “cold-freezing pain", "pain caused by light touch", "itching", "tingling or 'pins and needles,", and " "numbness"; and (d) affective descriptors (4 items): " "tiringexhausting", "sickening", "fearful", and "punishing-cruel" [3]. For each of these scales, scores were calculated by taking the mean of the item ratings included in the scale [3].

For VAS assessment, the patients were asked to mark their pain degree on the line between 'no pain' and 'the most severe pain'. The place of the mark was then measured in centimeters. VAS score $0 \mathrm{~cm}$ was categorized as no pain, 1-3 $\mathrm{cm}$ mild pain, 4-6 $\mathrm{cm}$ moderate pain and $7-10 \mathrm{~cm}$ severe pain [2].

For NRS assessment, the patients were asked to choose their pain degree on a number scale from zero to ten, with zero representing 'no pain' and ten representing 'the most severe pain ever felt.

Oral examination was carried out under natural lighting by examiners who had been previously calibrated and diagnoses were confirmed with radiographs and histology where appropriate.

The data analysis was done using the SPSS version 20 (IBM SPSS Armonk, New York) software. The mean pain assessment scores for the different dental conditions was compared using independent t-test/ANOVA where indicated. The correlation of the three pain assessment scales was done using Pearson correlation coefficient and $\mathrm{P}<0.05$ was considered statistically significant.

\section{RESUlTS}

A total of 83 participants were recruited for the study. Most (36.1\%) of the study participants were in 30-39 years age group. Their mean age was $38.2 \pm 14.0$ years with age range of 16 to 83 years. Majority 54(65.1\%) were female giving a male to female ratio of $1: 1.9$. More than two thirds of the patients had tertiary level of education as shown in Table I.

TABLE I: SOCIO-DEMOGRAPHIC VARIABLES OF STUDY PARTICIPANTS

\begin{tabular}{ccc}
\hline Variable & Frequency & $\%$ \\
\hline Age Group & & 4.8 \\
$10-19$ & 4 & 21.7 \\
$20-29$ & 18 & 36.1 \\
$30-39$ & 30 & 14.5 \\
$40-49$ & 12 & 14.5 \\
$50-59$ & 12 & 8.4 \\
$\geq 60$ & 7 & \\
Sex & & 34.9 \\
Male & 29 & 65.1 \\
Female & 54 & \\
& Highest level of education \\
None & 2 & 2.4 \\
Primary & 4 & 4.8 \\
Secondary & 18 & 21.7 \\
Tertiary & 59 & 71.1 \\
Occupation & & \\
Civil Servant & 22 & 26.5 \\
Self-Employed & 21 & 25.3 \\
Farmer & 20 & 24.1 \\
None & 14 & 16.9 \\
Artisan & 6 & 7.2 \\
Total & $\mathbf{8 3}$ & $\mathbf{1 0 0 . 0}$ \\
\hline
\end{tabular}

Neuropathic pain (SF-MPQ-2) was significantly higher in females compared to males $(\mathrm{p}=0.002)$. The other subscales of SF-MPQ-2 showed no statistically significant difference between males and females. Likewise, the mean SF-MPQ-2, VAS and NRS showed no statistically significant difference ( $\mathrm{p}=0.808,0.735$ and 0.952 respectively) between males and females (Table II).

TABLE II: COMPARISON OF THE MEAN PAIN SCORE For THE DIFFERENT PAIN ASSESSMENT SCALE BETWEEN GENDER USING INDEPENDENT T-TEST

\begin{tabular}{ccccc}
\hline & \multicolumn{2}{c}{ SEX } & & \\
\cline { 2 - 3 } & Mean $\pm \mathrm{SD}$ & Mean $\pm \mathrm{SD}$ & & \\
\cline { 2 - 3 } & T-Test & P-value \\
\cline { 2 - 3 } Continuous & $24.0 \pm 14.88$ & $20.76 \pm 14.85$ & 0.946 & 0.348 \\
Intermittent & $18.93 \pm 13.28$ & $17.83 \pm 14.91$ & 0.344 & 0.732 \\
Neuropathic & $10.79 \pm 13.13$ & $21.13 \pm 15.34$ & -3.219 & $0.002^{*}$ \\
Affective & $12.84 \pm 10.83$ & $9.11 \pm 10.67$ & 1.500 & 0.139 \\
SF-MPQ-2 & $66.56 \pm 40.28$ & $68.83 \pm 40.73$ & -0.245 & 0.808 \\
VAS & $5.33 \pm 2.45$ & $5.56 \pm 3.17$ & -0.340 & 0.735 \\
NRS & $5.48 \pm 2.18$ & $5.52 \pm 2.76$ & -0.060 & 0.952 \\
\hline
\end{tabular}

The mean VAS and NRS scores were highest for those diagnosed with acute apical periodontitis with mean scores of $6.68 \pm 2.36$ and $6.61 \pm 2.06$ respectively; and this finding was statistically significant. The clinical diagnosis with the second highest mean score for VAS was cancer; while that of 
NRS was space infections. Participants with chronic periodontitis had the lowest mean VAS and NRS scores. The SF-MPQ-2 pain assessment scale showed no significant difference among the different clinical diagnosis $(\mathrm{p}=0.338)$. However, the clinical diagnosis with the highest mean score of SF-MPQ-2 was acute apical periodontitis $(74.73 \pm 43.66)$ followed by pulpitis $(67.08 \pm 44.63)$. Pain from cancer had the lowest SF-MPQ-2 mean score (Table III).

TABLE III: RELATIONSHIP BETWEEN CLINICAL DIAGNOSIS AND PAIN ASSESSMENT SCORES USING SF-MPQ-2, VAS AND NRS USING ANOVA

\begin{tabular}{lccc}
\multicolumn{2}{c}{ ASSESSMENT SCORES USING SF-MPQ-2, VAS AND NRS USING ANOVA } \\
\cline { 2 - 4 } Clinical Diagnosis & SF-MPQ-2 & VAS & NRS \\
\cline { 2 - 4 } Acute Apical Periodontitis & $74.73 \pm 43.66$ & $6.68 \pm 2.36$ & $6.61 \pm 2.06$ \\
Chronic Periodontitis & $57.60 \pm 30.94$ & $2.50 \pm 1.85$ & $2.77 \pm 1.54$ \\
Cancer & $40.00 \pm 0.00$ & $6.50 \pm 0.00$ & $6.00 \pm 0.00$ \\
Pulpitis & $67.08 \pm 44.63$ & $5.42 \pm 2.99$ & $5.67 \pm 2.58$ \\
Space Infection & $42.33 \pm 18.23$ & $6.33 \pm 3.79$ & $6.33 \pm 2.08$ \\
\hline F & 1.153 & 12.74 & 14.67 \\
P-value & 0.338 & 0.000 & 0.000 \\
\hline
\end{tabular}

Using VAS pain assessment scales, patients with acute apical periodontitis and pulpitis presented with moderate to severe pain levels. Two thirds of those with space infection presented with severe pain. Most $(54.5 \%)$ of those with chronic periodontitis had mild pain. The only patient with cancer had severe pain (Table IV).

TABLE IV: RELATIONSHIP BETWEEN CLINICAL DIAGNOSIS AND PAIN SEVERITY USING VAS PAIN SCORES

\begin{tabular}{lcccccc}
\hline \multirow{4}{*}{$\begin{array}{c}\text { Clinical } \\
\text { diagnosis }\end{array}$} & $\begin{array}{c}\text { No Pain } \\
(\mathbf{0})\end{array}$ & $\begin{array}{c}\text { Mild } \\
\mathbf{( 1 - 3 )}\end{array}$ & $\begin{array}{c}\text { Moderate } \\
\mathbf{( 4 - 6 )}\end{array}$ & $\begin{array}{c}\text { Severe } \\
\mathbf{( 7 - 1 0 )}\end{array}$ & Total & $\begin{array}{c}\text { Chi- } \\
\text { square, } \\
\text { p-value }\end{array}$ \\
\cline { 2 - 6 } & $\mathrm{N}(\%)$ & $\mathrm{N}(\%)$ & $\mathrm{N}(\%)$ & $\mathrm{N}(\%)$ & & \\
\hline $\begin{array}{l}\text { Acute apical } \\
\text { Periodontitis }\end{array}$ & $0(0.0)$ & $4(7.8)$ & $17(33.3)$ & $30(58.8)$ & $51(61.4)$ & \\
$\begin{array}{l}\text { Space } \\
\text { Infection }\end{array}$ & $0(0.0)$ & $1(33.3)$ & $0(0.0)$ & $2(66.7)$ & $3(3.6)$ & 34.06, \\
$\begin{array}{l}\text { Pulpitis } \\
\text { Chronic }\end{array}$ & $0(0.0)$ & $1(16.7)$ & $3(50.0)$ & $2(33.3)$ & $6(7.2)$ & $<0.001$ \\
$\begin{array}{l}\text { Periodontitis } \\
\text { Cancer }\end{array}$ & $3(13.6)$ & $12(54.5)$ & $6(27.3)$ & $1(4.5)$ & $22(26.5)$ & \\
\hline
\end{tabular}

There was a significant strong positive correlation between VAS and NRS pain assessment tools. The correlation between SF-MPQ-2 and VAS/NRS was however, weak but statistically significant (Table V).

TABLE V. CORRELATION OF THE THREE PAIN ASSESSMENT SCALES

\begin{tabular}{llcc}
\hline & & VAS & NRS \\
\hline VAS & $\begin{array}{l}\text { Pearson } \\
\text { Correlation } \\
\text { P-value }\end{array}$ & & 0.924 \\
& $\mathrm{~N}$ & $0.000^{*}$ \\
& Pearson & 83 \\
\hline NRS & $\begin{array}{l}\text { Correlation } \\
\text { P-value }\end{array}$ & 0.924 & \\
& N & $0.000 *$ & \\
\hline SF-MPQ-2 & Pearson & 83 & \\
& Correlation & 0.315 & 0.308 \\
& P-value & $0.004 *$ & $0.005 *$ \\
& N & 83 & 83 \\
\hline Statistically significant. & & & \\
\hline
\end{tabular}

\section{DISCUSSION}

Pain is referred to as the fifth vital sign and is an important reason for which patients seek health care [13]. Measurement of pain is usually based on pain assessment scales that are dependent on the perception of the patient, patients' preference, age, gender and level of education [5], [14], [15]. Assessment of pain is essential in evaluating the appropriate treatment need of patients presenting with dental conditions because it equips the clinicians with the useful information on the best approach to treatment [15]. Also, the knowledge of the character and intensity of pain is essential in the management of patients with orofacial pain.

In this study we found that most of the patients presented with acute apical periodontitis followed by chronic periodontitis. This is similar to previous studies where most of the recorded orofacial pain were attributed to pulpal involvement and periodontal diseases [1], [2], [9]. The increase in the prevalence of acute pain among dental patients are due to late presentations to the clinic, poor access to dental facilities and self-treatment with antibiotics and analgesics [1], [9].

While the mean pain score of SF-MPQ-2, VAS and NRS showed no significant difference between males and females in this study, the neuropathic component of SF-MPQ-2 was significantly higher among the females. This reflect the effectiveness of the use of SF-MPQ-2 in the assessment of neuropathic pain when compared to VAS or NRS [16]. SFMPQ-2 not only assess the intensity of pain but also the quality of pain [8]. This is essential in the treatment and follow-up of patients with neuropathic dental pain. Previous studies also reported increase in the prevalence of neuropathic pain among females [17], [18]. The difference in the character of pain between males and females have been attributed to multiple biological and psychosocial factors [17].

Our study found that the mean scores for SF-MPQ-2, VAS and NRS were higher for acute dental pain when compare to chronic conditions. This is however expected as patient rating of acute pain are usually more than that of chronic conditions. The significant positive correlation between the three pain assessment scales is consistent with the results of most studies that consider these scales to be reliable and suitable for use in clinical practice. Also, a systematic review by Hjermstad et al. [11] showed that most of the reviewed papers were relatively consistent regarding the correlation between these pain assessment scales in direction and strength. While there was a strong correlation between VAS and NRS, the correlation between SF-MPQ-2 and either of VAS and NRS pain assessment scales was however weak. The reason for the weak relationship may have been due to the fact that although SF-MPQ-2 has components of NRS/VRS, the affective components may have accounted for the weak correlation, since SF-MPQ-2 is a multidimensional scale for pain assessment. Though SF-MPQ-2 is rarely used for the assessment of orofacial pain, the affective and neuropathic components will be useful in the management of chronic neuropathic pain such as trigeminal neuralgia. However further longitudinal studies will be necessary to ascertain its usefulness in the management of orofacial pain. A study by Hawker et al. [10], showed that SF-MPQ-2 can also be used in the clinical setting to measure acute dental pain, though it 
takes a little more time to complete compared to VAS and NRS.

Furthermore, VAS and NRS have been found to be more sensitive among the pain assessment scales [10], [11]. However, patients often prefer to communicate their pain in words rather than numbers [14]. Describing a non-localized pain of pulpal and periodontal origin is sometimes difficult and using a number to label such pain may not be sufficient [14], [15], [19]. SF-MPQ-2 can provide a comprehensive assessment of orofacial pain symptoms.

\section{CONCLUSION}

Severity of pain was highest among those with acute apical periodontitis using the three pain assessment tools. The participants with cancer had the lowest SF-MPQ-2 mean scores while those with chronic periodontitis have the lowest score using VAS and NRS. There was a significant positive correlation between SF-MPQ-2, VAS and NRS for dental pain assessment

\section{CONFLICT OF INTEREST}

The authors declare no potential conflicts of interest with respect to the research, authorship, and/or publication of this article.

\section{ACKNOWLEDGMENT}

We would like to thank the study participants.

\section{REFERENCES}

[1] Omitola OG, Arigbede AO. Prevalence and pattern of pain presentation among patients attending a tertiary dental center in a southern region of Nigeria. J Dent Res Dent Clin Dent Prospects. 2010;4(2):42-46.

[2] Odai ED, Ehizele AO, Enabulele JE. Assessment of pain among a group of Nigerian dental patients. BMC Res Notes. 2015;19(8):251.

[3] Turk DC, Okifuji A. Psychological factors in chronic pain: Evolution and revolution. J Consult Clin Psychol. 2002;70(3):678.

[4] Welchek CM, Mastrangelo L, Sinatra RS, Martinez R. Qualitative and quantitative assessment of pain. Acute Pain Manag. 2009;27(147):171.

[5] Kachooei AR, Ebrahimzadeh MH, Erfani-Sayyar R, Salehi M, Salimi E, Razi S. Short Form-McGill Pain Questionnaire-2 (SF-MPQ-2): a crosscultural adaptation and validation study of the Persian version in patients with knee osteoarthritis. ABJS. 2015;3(1):45.

[6] Melzack R. The short-form McGill Pain Questionnaire. Pain. 1987;30:191-7.

[7] Dworkin RH, Turk DC, Revicki DA, Harding G, Coyne KS, PeirceSandner S, et al. Development and initial validation of an expanded and revised version of the Short-form McGill Pain Questionnaire (SF-MPQ2). Pain. 2009;144:35-42.

[8] Gauthier LR, Young A, Dworkin RH, Rodin G, Zimmermann C, Warr D, et al. Validation of the Short-Form McGill Pain Questionnaire-2 in Younger and Older People with Cancer Pain. J Pain. 2014; 15(7):75670 .

[9] Ibikunle AA, Adeyemo WL, James O. Comparison of two pain assessment tools in patients undergoing routine dental extraction. Nig Oral Maxillofac Surg. 2014;1:32-36.

[10] Hawker GA, Mian S, Kendzerska T, French M. Measures of adult pain: Visual analog scale for pain (vas pain), numeric rating scale for pain (nrs pain), mcgill pain questionnaire (mpq), short-form mcgill pain questionnaire (sf-mpq), chronic pain grade scale (cpgs), short form-36 bodily pain scale (sf-36 bps), and measure of intermittent and constant osteoarthritis pain (icoap). Arthrit Care Res. 2011;63(11):240-52.

[11] Hjermstad MJ, Fayers PM, Haugen DF, Caraceni A, Hanks GW, Loge JH, et al. Studies comparing Numerical Rating Scales, Verbal Rating Scales, and Visual Analogue Scales for assessment of pain intensity in adults: a systematic literature review. J Pain Symptom Manag. 2011; 41(6):1073-1093.
[12] Welsh EM, Gettinby G, Nolan AM. Comparison of a visual analogue scale and a numerical rating scale for assessment of lameness, using sheep as a model. Am J Vet Res. 1993;54(6):976.

[13] Khatri A, Kalra N. A comparison of two pain scales in the assessment of dental pain in East delhi children. ISRN dentistry. 2012;2012.

[14] dos Santos Calderon P, Fernandes Peixoto R, Maron Gomes V, da Mota Corrêa AS, de Alencar EN, Nunes Rossetti LM, Rodrigues Conti PC. Concordance among different pain scales in patients with dental pain. J Orofac Pain. 2012;26(2):126.

[15] Clark P, Lavielle P, Martínez H. Learning from pain scales: Patient perspective. J Rheumatol. 2003; 30:1584-88.

[16] Lovejoy TI, Turk DC, Morasco BJ. Evaluation of the psychometric properties of the revised short-form McGill Pain Questionnaire. J. Pain Res. 2012;13(12):1250-7.

[17] Bartley EJ, Fillingim RB. Sex differences in pain: a brief review of clinical and experimental findings. Br. J. Anaesth. 2013;111(1):52-8.

[18] Rokyta R, Yamamotová A. Sex differences in pain perception and interpretation. Activitas Nervosa Superior Rediviva. 2013;55(3):125-34

[19] Zheng J, McMillan AS, Wong MC, Luo Y, Lam CL. Investigation of factors associated with treatment-seeking in southern Chinese with orofacial pain. J Orofac Pain 2010; 24:181-188. 